\title{
O “PREÇO” DO VOTO E OS “CUSTOS” SOCIAIS DAS CAMPANHAS ELEITORAIS NO BRASIL
}

\author{
the "price" of the vote and the "social costs" of the electoral campaigns in Brazil
}

\author{
Francisco Fransualdo de Azevedo *
}

\begin{abstract}
Resumo
A cada campanha eleitoral no Brasil, valores cada vez mais elevados são gastos pelos candidatos e partidos políticos. Isso evidencia a necessidade de uma ampla reforma política, associada à criação de mecanismos que garantam o cumprimento de um sistema de leis que venha a alterar esse quadro. Normalmente, quem arca com esses ônus é a própria sociedade. Antes de 1993, sequer existia no Brasil uma normatização legal sobre os gastos dos políticos nas campanhas eleitorais, o que implicava a não obrigatoriedade da prestação de contas dos mesmos. A partir das eleições de 1994, ou seja, só recentemente, a prestação de contas sobre receitas e despesas dos candidatos e partidos tornou-se obrigatória. Nesse contexto, analisaremos a prestação de contas, de uma parte dos candidatos do território brasileiro, nas últimas campanhas eleitorais realizadas no país, mostrando as fontes de financiamento, possíveis finalidades e montantes transacionados. Para isso, analisaremos textos relacionados ao tema, assim como dados coletados junto a órgãos como o Tribunal Superior Eleitoral e o Instituto Brasileiro de Geografia e Estatística.
\end{abstract}

Palavras-chave:Preço do voto, Campanha eleitoral, Receita, Despesa, Custo social.

\begin{abstract}
At every electoral campaign in Brazil, more money is spent by candidates and political parties. That shows the need for an ample political reform as well as for the creation of mechanisms which can guarantee the execution of the law system that would alter that picture. Society itself usually is the one to pay that bill. Before 1993, there ware not even legal regulations concerning the expenses by the politicians in their electoral campaigns, that meant that politicians were not obliged to give account of their expenses. That picture started to change since 1994 elections. In other words, only recently accounts rendered on revenues and candidates' expenses and parties became obligatory. Thus, the focus of the analysis will be the accounts of part of the candidates of the Brazilian territory in the last electoral campaigns, showing sources of financing, possible purposes as well as amounts negotiated. The data will be composed of texts related to the theme as well as of documents collected from institutions such as the "Tribunal Superior Eleitoral" and the Brazilian Institute of Geography and Statistics.
\end{abstract}

Key words: Price of the vote, Electoral campaign, Revenue, Expenses, Social costs

\begin{abstract}
Resumen
En cada campaña electoral en Brasil, los candidatos y partidos políticos realizan gastos cada vez más elevados Esto pone en evidencia la necesidad de una amplia reforma política, asociada a la creación de mecanismos que garanticen el cumplimiento de un sistema de leyes que venga a alterar este cuadro. Usualmente, quien se hace cargo de esos costes es la propia sociedad. Antes de 1993, ni siquiera existía en Brasil una normativa legal sobre los gastos de los políticos en las campañas electorales, o que implicase una no obligatoriedad de rendición de cuentas. A partir de las elecciones de 1994, es decir recientemente, la presentación de cuestas sobre ingresos y gastos de los candidatos se hizo obligatoria. En ese contexto, analizaremos la presentación de cuentas, de un parte de los candidatos del territorio brasileño, en las últimas campañas electorales realizadas en el país, mostrando las fuentes de financiamiento, posibles fines y cantidades negociadas. Para eso, analizaremos los textos relacionados con el tema, así como los datos recogidos por órganos tales como el Tribunal Superior Electoral o el Instituto Brasileño de Geografía y Estadística.
\end{abstract}

Palabras claves: Precio del voto, Campaña electoral, Ingresos, Gastos, Coste social.

(*) Prof. Dr. do Programa de Pós-Graduação em Geografia da Universidade Federal do Rio Grande do Norte - Caixa Postal 1524, Campus Universitário Lagoa Nova, CEP: 59078-970, Natal (RN), Brasil . Tel/Fax: (+55 84) 32153569 - ffazevedo@gmail.com 


\section{INTRODUÇÃO}

Em vários países, o dinheiro se constitui, muitas vezes, numa condição sine qua non à manutenção e à reprodução de agentes e grupos políticos no poder. No Brasil ele é decisório para a manutenção desses, por conseguinte, para a sustentação e reprodução das oligarquias regionais.

Até 1993, não existia no Brasil uma normatização ou legislação que fiscalizasse os gastos dos partidos políticos e dos próprios candidatos nas campanhas eleitorais, o que implicava a não obrigatoriedade da prestação de contas por parte desses. Somente a partir das eleições de 1994 é que isso se tornou obrigatório, ou seja, as receitas e despesas das campanhas eleitorais dos candidatos e partidos passaram a ser declaradas junto ao Tribunal Eleitoral.

Sabe-se que a cada campanha eleitoral, montantes cada vez maiores são gastos para financiar as despesas dos candidatos, do tipo: viagens, propaganda e publicidade - falada, impressa e televisiva -, comícios, produções audiovisuais, serviços prestados por terceiros, despesa com pessoal, locação de bens móveis e imóveis, cachês de artistas e animadores. Até recentemente gastava-se valores exorbitantes com camisetas, bonés e outros produtos. Continuam sendo transacionados altos montantes em doações a candidatos ou comitês, elevados gastos com combustíveis e lubrificantes, pesquisas de intenção de votos ou testes eleitorais, e outros tipos de gastos com equipamentos, bens e materiais permanentes de escritório, correios, água, luz, telefone, lanches e refeições, dentre outras despesas.

Em meio a tais despesas, admissíveis e reconhecidas pelos órgãos fiscalizadores, algumas estratégias podem ser adotadas pelos candidatos e partidos no sentido de burlarem as prestações de contas, de modo que os recursos declarados podem ser, às vezes, utilizados para outros fins como compra de votos, compra de bens e/ou serviços para serem doados aos eleitores, pagamento por apoio político de determinadas personalidades influentes nas bases locais, entre outras finalidades. Assim, valores não declarados no processo de prestação de contas também podem servir para esses fins, portanto, transações não mensuráveis e fiscalizadas pelos órgãos fiscalizadores do Estado.

Nesse sentido, buscaremos analisar os gastos de alguns candidatos nas últimas campanhas eleitorais realizadas no Brasil, e especificamente no estado do Rio Grande do Norte, mostrando as fontes de financiamento, montantes dos recursos por candidato e/ou partido e suas respectivas finalidades. $\mathrm{O}$ estudo se desenvolverá com base na análise e depreensão de textos relacionados ao tema, bem como a partir de análises de dados coletados junto a órgãos como o Tribunal Superior Eleitoral e o Instituto Brasileiro de Geografia e Estatística.

\section{O “PREÇO DO VOTO” E OS “CUSTOS” SOCIAIS DAS CAMPANHAS ELEITORAIS BRASILEIRAS: discutindo a realidade nacional e do estado do Rio Grande do Norte}

Ao analisar os dados sobre os financiamentos das campanhas eleitorais no Brasil e sugerir uma reforma política, Samuels (2006, p. 134) afirma que "as quantias declaradas não refletem completamente as quantias de fato usadas". Além disso, notam-se fortes disparidades nos montantes gastos entre os partidos e entre os candidatos, às vezes, de um mesmo partido.

Além das contribuições do fundo partidário, normalmente elevadas, o setor empresarial tem contribuído substancialmente com os partidos e candidatos, muito mais do que as pessoas físicas, e "a maior parte dos contribuintes empresariais vem (não é à toa) de setores grandemente influenciados por regulamentação governamental ou muito dependentes de contratos públicos: bancos, setor financeiro, indústria pesada, construção civil" (SAMUELS, 2006, P. 134).

Somando apenas as receitas declaradas ao Tribunal Superior Eleitoral, portanto, as contribuições do "caixa um" (dados oficiais) dos candidatos à presidência da República nas eleições de 1994, 1998 e 2002 no Brasil, tem-se um montante de aproximadamente R $\$ 235$ milhões de reais (tabela 1).

Nota-se que os valores das receitas são bastante díspares entre os candidatos. Por exemplo, Fernando Henrique Cardoso (PSDB) declarou o maior montante na receita das campanhas eleitorais 
de 1994 e 1998, eleições em que o candidato do PT, Luiz Inácio Lula da Silva, declarou valores ínfimos em relação ao seu principal adversário. Em 1998, o candidato do PSDB se reelegeu com maioria expressiva de votos. Já em 2002, o candidato do PT, eleito presidente da República no segundo turno, declarou maior receita, seguido de José Serra (PSDB), Ciro Gomes (PPS) e Anthony Garotinho (PSB). Assim, verifica-se que nesses três pleitos eleitorais os vencedores foram aqueles que dispunham de maior volume de recursos em suas campanhas eleitorais.

Tabela 1 - Brasil: Receitas das campanhas eleitorais presidenciais e percentuais de votos por candidato (1994, 1998 e 2002)

\begin{tabular}{|c|c|c|c|c|}
\hline Ano & Candidato/Partido & $\begin{array}{c}\text { Receitas } \\
\text { (RS 1,00) } \\
\end{array}$ & $\begin{array}{c}\text { (\%) em relação ao } \\
\text { total por eleição }\end{array}$ & Votação (\%) \\
\hline \multirow{4}{*}{1994} & Fernando Henrique Cardoso (PSDB) & $77.259 .290,00$ & 74,35 & 54,3 \\
\hline & Luiz Inácio Lula da Silva (PT) & $3.125 .494,00$ & 3,01 & 27,0 \\
\hline & Orestes Quércia (PMDB) & $23.052 .571,00$ & 22,19 & 4,4 \\
\hline & Esperidião Amin (PPR) & $470.937,00$ & 0,45 & 2,7 \\
\hline \multicolumn{2}{|c|}{ Total da campanha } & 103.908.292,00 & & \\
\hline \multirow{3}{*}{1998} & Fernando Henrique Cardoso (PSDB) & $66.363 .204,00$ & 92,74 & 53,1 \\
\hline & Luiz Inácio Lula da Silva (PT) & $3.572 .438,00$ & 4,99 & 31,7 \\
\hline & Ciro Gomes (PPS) & $1.622 .729,00$ & 2,27 & 11,0 \\
\hline \multicolumn{2}{|c|}{ Total da campanha } & 71.558.371,00 & & \\
\hline \multirow{4}{*}{2002} & José Serra (PSDB) & $18.177 .712,00$ & 30,70 & 23,2 \\
\hline & Luiz Inácio Lula da Silva (PT) & $26.589 .234,00$ & 44,91 & 46,4 \\
\hline & Ciro Gomes (PPS) & $13.028 .981,00$ & 22,01 & 12,0 \\
\hline & Anthony Garotinho (PSB) & $1.411 .265,00$ & 2,38 & 17,9 \\
\hline \multicolumn{2}{|c|}{ Total da campanha } & $59.207 .192,00$ & & \\
\hline
\end{tabular}

Fonte: SAMUELS, 2006, p. 135

Diante do exposto, somando-se as despesas totais declaradas por todos os candidatos que concorreram aos cargos de presidente da República, senador, governador, deputados federais e estaduais, estima-se, só em 1994, um valor "entre US\$ 3,5 e US\$ 4,5 bilhões. Em contraste, os candidatos gastaram cerca de US\$ 3 bilhões em eleições nos Estados Unidos em 1996. Em 1994 e 1998, Fernando Henrique declarou ter gastado mais de US\$ 40 milhões em sua campanha" (SAMUELS, 2006, P. 138), com um importante diferencial, no Brasil os candidatos não pagam pela propaganda eleitoral, no rádio e na televisão, ao passo que nos Estados Unidos, e na maioria dos países europeus, boa parte dos custos de campanha corresponde a essas despesas.

Portanto, trata-se de gastos excessivamente altos em campanhas eleitorais de um país subdesenvolvido como o Brasil. Vale ressaltar, com base no citado autor, que a maior parte do capital financiador das campanhas eleitorais no Brasil sai do setor empresarial, parte dele constituído por empresas que prestam, prestaram ou pretendem prestar serviços ao Estado.

É importante lembrar que Fernando Henrique Cardoso permaneceu no governo por mais de uma década, quando considerado o período em que o mesmo foi Ministro das Relações Exteriores, depois da Fazenda, no governo Itamar Franco, depois Presidente da República por dois mandatos. Vale lembrar que ao longo de todo este período, o mesmo conseguiu estimular fortemente o neoliberalismo econômico no Brasil, no qual o setor empresarial foi o mais beneficiado, especialmente as instituições financeiras, bancos e empresas que adquiriram patrimônios públicos, a exemplo das telecomunicações. Boa parte dessas empresas, ou suas acionistas, financiou as campanhas eleitorais do então candidato e, de alguma forma, continuam financiando as campanhas recentes, por exemplo, em 2006. É evidente que esses “contribuintes esperam um 'serviço' específico que apenas um cargo público pode oferecer em retorno pelo seu investimento” (SAMUELS, 2006, p. 147). 
Em relação aos gastos totais das eleições de 2002, o valor pode ser estimado "entre 3 e 4 bilhões de reais. Dessa forma, o fundo público seria apenas uma pequena parcela do que é realmente investido. Resultado: institucionalização do caixa dois" (FIGUEIREDO FILHO, 2006, p. 9). Em 2006, isso ficou mais evidente através dos escândalos de corrupção, mesmo que manipulados, mas, de alguma forma, divulgados pela mídia, envolvendo políticos que utilizaram "caixas dois" nas campanhas eleitorais dos seus partidos.

O TSE estima que os gastos da campanha eleitoral de 2006 somam aproximadamente R\$ 1,5 bilhão de reais. Só os candidatos, Luiz Inácio Lula da Silva (PT) e Geraldo Alckmin (PSDB), declararam gastos respectivos de R \$ 104,3 milhões e R \$ 81,9 milhões. As instituições financeiras e bancárias constituem a principal fonte de recursos, ao menos na categoria pessoa jurídica, para a campanha do PSDB. O Banco Itaú contribuiu com R\$ 3,5 milhões, o Banco Mercantil de São Paulo, pertencente ao grupo Bradesco, com R\$ 2 milhões, o Banco Alvorada, também controlado pelo Bradesco, contribuiu com R\$1,2 milhão, o Banco Real com R\$1,5 milhão, o Unibanco com R\$ 1,3 milhão, o Banco Safra com R\$ 750 mil. Empresas de mineração e siderurgia também fizeram doações expressivas ao PSDB, mais de R\$ 6 milhões. O grupo Gerdau doou R\$ 3 milhões, a Ibar Administrações, pertencente ao grupo Votorantim, doou R\$ 2,6 milhões (CONGRESSO EM FOCO, 2006a).

Em 2006, os gastos da campanha eleitoral do candidato/presidente, Luiz Inácio Lula da Silva (PT), foram superelevados em relação às eleições presidenciais de 2002. Considerando os valores atualizados, que correspondem a aproximadamente R \$ 52,4 milhões, o candidato gastou o dobro do que foi gasto na eleição anterior. As instituições que se destacaram em valores doados ao PT nessa campanha foram: o Grupo Camargo Correia que contribuiu com R \$ 3,5 milhões, o grupo Gerdau com R \$ 3,1 milhões, a Cutrale com R \$ 4,0 milhões e o Banco Itaú com R \$ 3,5 milhões. Também aparecem várias doações de empresas ligadas ao setor da construção e engenharia civil, além de pessoas físicas, políticos vinculados ao partido, entre outras (CONGRESSO EM FOCO, 2006b).

Assim, os gastos da campanha eleitoral deste ano (2006) foram superelevados em relação às campanhas anteriores, ao menos no que diz respeito aos valores declarados pelos candidatos mais votados. Isso indica, "possivelmente", uma maior lisura dos partidos e candidatos na prestação de contas junto ao TSE.

Entretanto, não obstante os graves problemas sociais enfrentados pela população brasileira, o país ultrapassa, em gastos de campanhas eleitorais, vários países desenvolvidos como a Alemanha e a Grã-Bretanha. Numa das últimas campanhas eleitoral alemã, os partidos de Angela Merkel e Gerhard Schroder investiram o equivalente a R 134 milhões. Em 2005, na Grã-Bretanha, o Partido Trabalhista e o Partido Conservador gastaram o equivalente a R 144 milhões, ou seja, valores bastante inferiores em relação ao Brasil (REVISTA ÉPOCA, 2006). Vale lembrar que a Grã-Bretanha conta com um rigoroso sistema de fiscalização e controle quanto a esse processo eleitoral e de prestação de contas de candidatos.

Nas eleições para governadores dos estados, os gastos das campanhas eleitorais também foram bastante elevados. Os três candidatos que apresentaram maiores gastos foram: José Serra (PSDB-SP), com R\$25,9 milhões, Aécio Neves (PSDB-MG), com R\$ 19,4 milhões, e Cid Gomes (PSB-CE), com R\$ 11,0 milhões.

No Rio Grande do Norte, os gastos também se apresentam bastante elevados, tendo em vista o perfil e o tamanho do estado, ou seja, um estado pequeno e cuja pobreza ainda é bastante significativa. A candidata reeleita em 2006, Wilma de Faria (PSB), declarou aproximadamente R $\$ 4,9$ milhões de reais de despesas na campanha eleitoral daquele ano, enquanto o candidato, Garibaldi Alves Filho (PMDB), declarou mais de R\$ 5,0 milhões de reais. (Tabela 2).

Ainda com relação as campanhas eleitorais de 2006, analisando o contexto regional, nota-se uma tendência semelhante em nível de estados nordestinos, tendência essa marcada por gastos elevados entre os candidatos. Depois do estado do Ceará, Alagoas foi um dos que apresentou maior despesa na campanha eleitoral para governador em 2006, isto é, $\mathrm{R} \$ 7,7$ milhões do candidato elei- 
to Teotônio Vilela Filho (PSDB) e R \$ 8,0 milhões do candidato João Lyra (PTB). Entretanto, se verifica na região Nordeste, algumas situações em que o candidato eleito gastou valores bastante inferiores se comparado ao adversário derrotado, por exemplo, na Bahia, onde o candidato eleito, Jaques Wagner (PT), gastou R \$ 4,2 milhões, já seu adversário, segundo colocado, Paulo Souto (PFL), gastou R\$ 9,2 milhões, quando se considera apenas os dados oficiais (REVISTA CONSULTOR JURÍDICO, 2006).

Tabela 2 - Rio Grande do Norte: Receitas e despesas da campanha eleitoral, votação, situação e percentual de votos por candidato, 2006

\begin{tabular}{|c|c|c|c|c|c|c|}
\hline Nome do Candidato/Partido & Candidatura & Receita & Despesa & Situação & Votação & $\%$ \\
\hline Wilma de Faria (PSB) & Governador & $4.895 .066,96$ & $4.895 .066,96$ & $1^{\circ}$ - Eleita & 824.101 & 52,38 \\
\hline Garibaldi Alves Filho (PMDB) & Governador & $5.016 .533,20$ & $5.016 .439,14$ & $2^{\circ}$ - Não Eleito & 749.172 & 47,62 \\
\hline Rosalba Ciarlini Rosado & Senador & $767.220,66$ & $767.043,19$ & $1^{\circ}$ - Eleita & 645.869 & 44,18 \\
\hline Fernando Bezerra (PTB) & Senador & $2.755 .328,34$ & $2.753 .641,87$ & $2^{\circ}$ - Não Eleito & 634.738 & 43,42 \\
\hline Geraldo José de Melo (PSDB) & Senador & $1.074 .215,25$ & $1.074 .196,20$ & $3^{\circ}$ - Não Eleito & 155.608 & 10,65 \\
\hline Fábio Faria (PMN) & Dep. Federal & $612.700,00$ & $612.223,70$ & $1^{\circ}$ - Eleito & 195.148 & 12,02 \\
\hline João Maia (PL) & Dep. Federal & $542.323,34$ & $541.299,99$ & $2^{\circ}$ - Eleito & 193.296 & 11,9 \\
\hline Henrique Eduardo Alves (PMDB) & Dep. Federal & $733.358,00$ & $733.091,56$ & $3^{\circ}$ - Eleito & 156.581 & 9,64 \\
\hline Rogério Marinho (PSB) & Dep. Federal & $250.786,50$ & $250.644,76$ & $4^{\circ}$ - Eleito & 130.063 & 8,01 \\
\hline Felipe Maia (PFL) & Dep. Federal & $648.600,00$ & $648.409,66$ & $5^{\circ}$ - Eleito & 124.382 & 7,66 \\
\hline Maria de Fátima Bezerra (PT) & Dep. Federal & $301.626,00$ & $301.621,08$ & $6^{\circ}$ - Eleita & 116.243 & 7,16 \\
\hline Nélio Dias (PP) & Dep. Federal & $262.651,80$ & $262.441,93$ & $7^{\circ}$ - Eleito & 93.245 & 5,74 \\
\hline Sandra Rosado (PSB) & Dep. Federal & $180.789,86$ & $180.187,50$ & $8^{\circ}$ - Eleita & 69.277 & 4,27 \\
\hline Robinson Mesquita de Faria (PMN) & Dep. Estadual & $495.960,00$ & $495.553,60$ & $1^{\circ}$ - Eleito & 70.782 & 4,31 \\
\hline Walter Pereira Alves (PMDB) & Dep. Estadual & $172.400,40$ & $172.400,04$ & $2^{\circ}$ - Eleito & 55.296 & 3,37 \\
\hline Márcia Faria Maia Mendes (PSB) & Dep. Estadual & $195.024,15$ & $195.023,31$ & $3^{\circ}$ - Eleita & 53.349 & 3,25 \\
\hline Gesane Borges Marinho (PDT) & Dep. Estadual & $153.449,08$ & $153.435,26$ & $4^{\circ}$ - Eleita & 46.221 & 2,82 \\
\hline Leonardo da Vinci L. Nogueira (PFL) & Dep. Estadual & $365.000,00$ & $364.797,93$ & $5^{\circ}$ - Eleito & 45.975 & 2,80 \\
\hline Francisco Gilson Moura (PV) & Dep. Estadual & $116.215,00$ & $116.105,72$ & $6^{\circ}$ - Eleito & 45.364 & 2,76 \\
\hline Micarla Araújo de Sousa Weber (PV) & Dep. Estadual & $166.019,05$ & $165.445,71$ & $7^{\circ}$ - Eleita & 43.936 & 2,68 \\
\hline Nelter L. de Queiroz Santos (PMDB) & Dep. Estadual & $138.279,39$ & $138.279,39$ & $8^{\circ}$ - Eleito & 42.042 & 2,56 \\
\hline Antônio Jácome de L. Júnior (PMN) & Dep. Estadual & $268.360,00$ & $268.241,83$ & $9^{\circ}$ - Eleito & 40.774 & 2,48 \\
\hline Gustavo Henrique L. de Carvalho (PSB) & Dep. Estadual & $258.374,29$ & $258.374,29$ & $10^{\circ}$ - Eleito & 40.632 & 2,48 \\
\hline Álvaro Costa Dias (PDT) & Dep. Estadual & $200.600,00$ & $200.413,51$ & $11^{\circ}$ - Eleito & 40.040 & 2,44 \\
\hline Ricardo J. Meirelles da Motta (PMN) & Dep. Estadual & $126.400,00$ & $126.384,62$ & $12^{\circ}$ - Eleito & 36.998 & 2,25 \\
\hline Ezequiel Galvão F. de Souza (PMN) & Dep. Estadual & $130.025,00$ & $129.962,63$ & $13^{\circ}$ - Eleito & 36.784 & 2,24 \\
\hline Lavoisier Maia Sobrinho (PSB) & Dep. Estadual & $159.900,00$ & $159.868,29$ & $14^{\circ}$ - Eleito & 35.278 & 2,15 \\
\hline Larissa D. da Escóssia Rosado (PSB) & Dep. Estadual & $138.043,92$ & $137.885,03$ & $15^{\circ}$ - Eleita & 34.073 & 2,08 \\
\hline Raimundo Nonato P. Fernandes (PMN) & Dep. Estadual & $59.597,60$ & $59.597,42$ & $16^{\circ}$ - Eleito & 33.903 & 2,07 \\
\hline Wober L. Pinheiro Júnior (PPS) & Dep. Estadual & $200.270,00$ & $200.270,00$ & $17^{\circ}$ - Eleito & 33.007 & 2,01 \\
\hline José Adécio Costa (PFL) & Dep. Estadual & $190.109,92$ & $190.109,92$ & $18^{\circ}$ - Eleito & 32.122 & 1,96 \\
\hline Luiz Almir F. Magalhães (PSDB) & Dep. Estadual & $112.500,00$ & $112.495,45$ & $19^{\circ}$ - Eleito & 31.064 & 1,89 \\
\hline Francisco P. Cavalcanti Júnior (PMDB) & Dep. Estadual & $44.085,00$ & $44.050,32$ & $20^{\circ}$ - Eleito & 30.678 & 1,87 \\
\hline José Dias de S. Martins (PMDB) & Dep. Estadual & $137.500,00$ & $137.241,40$ & $21^{\circ}$ - Eleito & 29.973 & 1,83 \\
\hline Getúlio Nunes do Rêgo (PFL) & Dep. Estadual & $116.500,00$ & $116.477,77$ & $22^{\circ}$ - Eleito & 29.298 & 1,79 \\
\hline Fernando W. Vargas da Silva (PT) & Dep. Estadual & $101.616,00$ & $100.962,65$ & $23^{\circ}$ - Eleito & 22.433 & 1,37 \\
\hline Arlindo Duarte Dantas (PHS) & Dep. Estadual & $44.548,44$ & $44.548,44$ & $24^{\circ}$ - Eleito & 20.074 & 1,22 \\
\hline
\end{tabular}

Fonte: TSE, 2006.

No Rio Grande do Norte, os candidatos ao senado também apresentaram gastos bastante expressivos, como é o caso do candidato Fernando Bezerra (PTB) que declarou valor superior a R $\$ 2,5$ 
milhões; o candidato Geraldo Melo (PSDB) declarou mais de R \$ 1,0 milhão, e a candidata eleita, Rosalba Ciarlini Rosado (PFL), declarou aproximadamente R 767 mil. Nesse estado, considerando os dados oficiais, nota-se que tanto nas candidaturas ao governo, quanto nas candidaturas ao senado, as maiores despesas não resultaram na vitória dos seus respectivos candidatos.

Despesas bastante elevadas também foram apresentadas pela maioria dos candidatos a deputado federal. Os dados mostram que Henrique Eduardo Alves (PMDB) sobressaiu como o candidato com maiores gastos na campanha de 2006, seguido de Felipe Maia (PFL), Fábio Faria (PMN) e João Maia (PL); juntos os mesmos gastaram aproximadamente $\mathrm{R} \$ 2,6$ milhões, os demais candidatos somaram um total aproximado de $\mathrm{R} \$ 1$ milhão.

Vale salientar que o candidato Carlos Alberto Rosado (PFL) declarou aproximadamente R\$ 292 mil de despesa, porém atingiu a suplência de deputado federal, ou seja, gastou mais que alguns candidatos eleitos.

No total, os deputados federais eleitos gastaram aproximadamente $\mathrm{R} \$ 3,5$ milhões, enquanto os deputados estaduais, em maior número, gastaram em torno de R $\$ 4,0$ milhões. Assim, os candidatos a deputado estadual também declararam despesas bastante expressivas, destacando-se Robinson Faria (PMN), Leonardo da Vinci Nogueira (PFL), Antônio Jácome Júnior (PMN) e Gustavo Henrique Carvalho (PSB), os quais gastaram mais que alguns deputados federais eleitos. É possível perceber ainda que apenas dois candidatos declararam despesas inferiores a $\mathrm{R} \$ 50$ mil. Portanto, também no caso dos candidatos a deputado estadual, a idéia de que "quem paga mais é mais votado" valeu, ao menos, para os primeiros colocados nas urnas.

Já em relação às principais arrecadações dos candidatos ao governo em 2006, há várias fontes de recursos com valores bastante representativos, principalmente, no tocante às doações dos grupos empresariais nacionais de grande porte (Tabela 3).

Dentre os principais doares da campanha do PSB, destaca-se construtoras e companhias de engenharia, indústrias têxteis e agrícolas, indústrias de alimentos, hotéis, empresas do setor imobiliário, concessionária de veículos, além de pessoas físicas com elevadas doações, a exemplo de Carlos Weibil Neto que, de acordo com o jornal Tribuna do Norte, é um "empresário paulista do ramo de biodiesel que tem negócios com o governo federal e pretende construir uma usina em Mossoró" (TRIBUNA DO NORTE, 2006)..

Várias outras empresas também contribuíram com a campanha do PSB, destacando-se as dos seguintes setores econômicos: engenharia e construção civil, produção e/ou distribuição de alimentos, distribuição/comércio de medicamentos e equipamentos hospitalares, distribuição e comércio de combustíveis, prestação de serviços em geral, hotéis, além de doações do comitê financeiro do partido, de políticos e de diversas pessoas físicas.

Dos valores totais arrecadados pelo PSB, mais de $30 \%$ foram doados após o segundo turno das eleições, ou seja, depois da candidata ter sido reeleita (TRIBUNA DO NORTE, 2006). Entre as fontes de recursos financiadoras da campanha eleitoral da candidata acima, verifica-se multinacionais europeias que atuam na economia do estado. Os dez maiores doadores da campanha da referida candidata contribuíram com montantes entre R $\$ 100$ mil e R \$ 400 mil. Seguindo a tendência acima, observa-se que as arrecadações do candidato Garibaldi Alves Filho (PMDB) apresentaram algumas fontes similares às apresentadas anteriormente, evidenciando montantes doados mais elevados em alguns casos.

Nesse contexto, também se destacam empresas do setor de engenharia e construção civil, normalmente, empreiteiras que prestam serviços ao setor público, como também, bancos, indústrias têxteis, mineradoras, empresas do setor de comércio, distribuição de alimentos e bebidas, distribuidoras de combustíveis, indústrias de fertilizantes, usinas de açúcar e álcool, siderúrgicas, hotéis e resorts, além de agentes políticos e doadores como pessoas físicas.

Vale destacar que algumas das empresas analisadas pertencem ao mesmo grupo econômico, o que eleva os valores doados por cada grupo. Por exemplo, a Caemi tem ligação com a Companhia 
Vale do Rio Doce, a Companhia Siderúgica do Maranhão com a Companhia Siderúrgica Vale do Pindaré, entre outras conjugações.

A partir da análise detalhada dos dados é possível entender por que os grupos políticos permanecem no poder por tanto tempo, como é o caso das oligarquias potiguares. O dinheiro (lícito ou não) é vital para a manutenção e reprodução dos agentes e grupos políticos, por conseguinte, de grupos econômicos.

Analisando os dados do TSE referentes às prestações de contas dos candidatos ao senado, constatamos que boa parte das doações recebidas também se origina de algumas das empresas acima, porém, com acréscimos e contribuições de outros grupos e instituições (Tabela 4).

A ex-prefeita de Mossoró, candidata eleita como senadora pelo PFL em 2006, hoje governadora do estado, recebeu $65 \%$ do valor gasto na campanha do diretório regional do seu partido, aproximadamente $20 \%$ doado pela Companhia Vale do Rio Doce, 6,5\% doado pelo Banco Itaú, entre outras arrecadações menores de fontes diversas.

O usineiro, ex-governador e ex-senador, Geraldo José de Melo, candidato ao senado pelo PSDB, declarou arrecadações de empresas do próprio setor econômico do qual faz parte, bem como de construtoras, de fontes não identificáveis e parte significativa de recursos próprios. Vale frisar que membros da família deste candidato, a exemplo da esposa do mesmo, exerceu o cargo de prefeita no município de Ceará Mirim nesse período, município esse localizado na Região Metropolitana de Natal.

Tabela 3 - Rio Grande do Norte: Principais doações da campanha eleitoral - candidatos ao governo, 2006

\begin{tabular}{|c|c|c|c|}
\hline Candidato/Partido & Fonte de recursos & Valor (R\$ 1) & Data \\
\hline \multirow[t]{29}{*}{ Wilma de Faria } & Grupo Santana Têxtil S/A & $400.000,00$ & 17 e $20 / 11$ \\
\hline & Carlos Weibil Neto & $300.000,00$ & $13 / 11$ \\
\hline & Agroarte Empresa Agrícola S/A & $200.000,00$ & $15 / 09,17 / 08$ e $20 / 10$ \\
\hline & Pirâmide Palace Hotel Ltda & $190.000,00$ & $10 / 11$ \\
\hline & G Cinco Pan Execuções Ltda & $180.000,00$ & $10 / 11$ \\
\hline & Esse Engenharia Sinalização e Serviços & $165.000,00$ & $16 / 11$ \\
\hline & M. Dias Branco Ind. e Com. de Alimentos & $150.000,00$ & $07 / 08$ \\
\hline & Sanchez Brasil-Invest. Imobiliários Ltda & $150.000,00$ & $27 / 10$ \\
\hline & EC Engenharia e Consultoria Ltda & $119.500,00$ & $03 / 08,27 / 11$ e $03 / 08$ \\
\hline & Salinas Automóveis Ltda & $106.000,00$ & $14 / 09,27 / 0903 / 08$ \\
\hline & Delphi Engenharia Ltda & $100.000,00$ & $10 / 11$ \\
\hline & Guararapes Confecções S/A & $100.000,00$ & $18 / 09$ \\
\hline & Simas Industrial de Alimentos S/A & $100.000,00$ & $22 / 09$ \\
\hline & Tensacciai Indústria e Comércio Ltda & $100.000,00$ & $22 / 11$ \\
\hline & Posto Olinda & $99.000,00$ & $21 / 11$ \\
\hline & CRR Construções e Serviços Ltda & $96.000,00$ & $18 / 09,21 / 09$ e $03 / 11$ \\
\hline & Tecidos Líder Indústria e Comércio Ltda & $80.000,00$ & $29 / 08$ \\
\hline & Sta Clara Indústria e Comércio Alimentos Ltda & $73.000,00$ & $12 / 09$ e $02 / 10$ \\
\hline & Dois A Engenharia e Tecnologia Ltda & $73.000,00$ & $18 / 09$ e $03 / 11$ \\
\hline & MRG Instalações Elétricas e Hidráulicas Ltda & $60.000,00$ & $23 / 11$ \\
\hline & Coteminas S/A & $50.000,00$ & $25 / 10$ \\
\hline & Zumba Petróleo & $50.000,00$ & $28 / 08$ e $30 / 08$ \\
\hline & Diprofarma Distr. Prod. Farmacêuticos Ltda & $50.000,00$ & $17 / 08$ \\
\hline & DIA Distribuidora Internacional de Alimentos & $50.000,00$ & $15 / 09$ \\
\hline & CDA Central Distr. Azevedo & $50.000,00$ & $22 / 11$ \\
\hline & Astriel Vieira Mendonça Júnior & $50.000,00$ & $16 / 08$ e $25 / 09$ \\
\hline & Mercurius Construções Ltda & $50.000,00$ & $20 / 10$ \\
\hline & CROP Agrícola Ltda & $50.000,00$ & $27 / 11$ \\
\hline & Distribuidora de C. Natal Ltda & $50.000,00$ & $15 / 09$ \\
\hline
\end{tabular}




\begin{tabular}{|c|c|c|c|}
\hline \multirow{30}{*}{$\begin{array}{l}\text { Garibaldi Alves Filho } \\
\qquad \text { (PMDB) }\end{array}$} & Grupo Camargo Correa & $550.000,00$ & $18 / 10$ e $27 / 10$ \\
\hline & EMSA - Empresa Sul-americana de Montagem S/A & $450.000,00$ & $12 / 09,22 / 09$ e $18 / 10$ \\
\hline & Sanchez Brasil Investimentos Ltda & $370.000,00$ & $27 / 09$ e $27 / 10$ \\
\hline & Companhia Siderúrgica Nacional & $250.000,00$ & $15 / 09$ \\
\hline & Companhia Vale do Rio Doce & $200.000,00$ & $23 / 08$ \\
\hline & Mendes Júnior Trading e Engenharia S/A & $200.000,00$ & $23 / 10$ \\
\hline & Satélite Distribuidora de Petróleo S/A & $200.000,00$ & $18 / 08,08 / 09$ e $17 / 10$ \\
\hline & CR Almeida S/A & $200.000,00$ & 20/09 \\
\hline & FRATELLIVITA Bebidas S/A & $200.000,00$ & $16 / 08$ e $17 / 10$ \\
\hline & Coteminas S/A & $150.000,00$ & $12 / 09$ e $27 / 10$ \\
\hline & Henrique Eduardo Alves & $149.400,00$ & $11 / 08$ \\
\hline & Agroarte Empresa Agrícola S/A & $120.000,00$ & $27 / 09$ e $20 / 10$ \\
\hline & Cosima - Siderúrgica do Maranhão & $120.000,00$ & $26 / 09$ \\
\hline & Banco Fator S/A & $100.000,00$ & $10 / 08$ \\
\hline & Banco Itaú S/A & $100.000,00$ & $04 / 08$ \\
\hline & Bolsa de Mercadorias e Futuros BM\&F & $100.000,00$ & $09 / 08$ \\
\hline & Caemi - Mineração e Metalurgia S/A & $100.000,00$ & $10 / 10$ \\
\hline & Camter Construções e Empreendimentos & $100.000,00$ & $30 / 08$ \\
\hline & Caracas Construções Ltda & $100.000,00$ & $27 / 10$ \\
\hline & Guararapes Confecções S/A & $100.000,00$ & $26 / 07$ \\
\hline & Santa Clara Ind. Com. de Alimentos Ltda & $80.000,00$ & $23 / 08$ e $12 / 09$ \\
\hline & Fosfertil - Fertilizantes Fosfatos S/A & $75.000,00$ & $08 / 09$ e $11 / 10$ \\
\hline & M. Dias Branco Ind. e Com. de Alimentos Ltda & $75.000,00$ & $01 / 08$ \\
\hline & Ultrafertil S/A & $75.000,00$ & $08 / 09$ e $11 / 10$ \\
\hline & Ney Lopes de Souza & $64.500,00$ & $03 / 08$ e $10 / 10$ \\
\hline & Companhia Siderúrgica Vale do Pindaré & $60.000,00$ & $26 / 09$ \\
\hline & M. Amaral Cons. Assoc. S/C Ltda & $60.000,00$ & $11 / 08$ \\
\hline & Banco Alvorada S/A & $50.000,00$ & $27 / 10$ \\
\hline & Tavares de Melo Açúcar e Álcool S/A & $50.000,00$ & $22 / 09$ \\
\hline & Unibanco - União de Bancos Brasileiros & $50.000,00$ & $04 / 08$ \\
\hline
\end{tabular}

Fonte: TSE, 2006.

O industrial, empresário do setor de construção civil, ex-presidente da Confederação Nacional das Indústrias e do Serviço Nacional de Aprendizagem Industrial, candidato ao senado, Fernando Bezerra (PTB), declarou em sua receita, parte significativa de recursos próprios (35\%), como também doações do diretório do seu partido (22\%), além de valores expressivos doados por bancos, construtoras, indústrias, empresários, outras corporações, outras instituições e pessoas físicas.

Em geral, as receitas dos candidatos a deputados federal e estadual também se constituem em doações feitas por instituições que participaram dos financiamentos das campanhas dos candidatos à presidência da República, ao Governo do Estado e ao senado, ampliando-se consideravelmente para outros segmentos econômicos, como os representados por empresas do setor de transportes, do setor salineiro, empresas jornalísticas, grupos do agronegócio, logísticas, locadoras de veículos, além de uma relação extensa de valores doados por pessoas físicas, às vezes, contribuintes de valores bastante elevados.

Entretanto, construtoras, bancos, companhias mineradoras, siderúrgicas, indústrias de alimentos, empresas comerciais, recursos dos próprios candidatos e parentes, bem como os recursos dos comitês dos partidos, destacam-se em termos de montantes de dinheiro que formam a maior parte das receitas, por conseguinte do financiamento das campanha eleitorais no Brasil e no Rio Grande do Norte. Assim, é visível a estreita relação do poder econômico com o poder político, podendo-se afirmar que existe uma relação simbiótica entre ambos, haja vista o volume de recursos levantados nas últimas eleições. 
Tabela 4 - Rio Grande do Norte: Principais doações da campanha eleitoral - candidatos (a) ao senado da República, 2006

\begin{tabular}{l|c|c|c}
\hline Candidato/Partido/Situação & Fonte de recursos & Valor (RS 1 & Data \\
\hline \multirow{3}{*}{ Rosalba Ciarlini Rosado } & Banco Itaú S/A & $50.000,00$ & $03 / 08$ \\
\cline { 2 - 4 } (PFL) - Eleita & Companhia Vale do Rio Doce & $150.000,00$ & $23 / 08$ \\
\cline { 2 - 4 } & Diretório Regional PFL-RN & $500.000,00$ & $21 / 09$ e 26/09 \\
\cline { 2 - 4 } & Cia Açucareira Vale Ceará Mirim & $123.950,00$ & $24 / 07,10$ e 31/08, 01/09 \\
\cline { 2 - 4 } Geraldo José de Melo & Bunge Fertilizantes S/A & $80.000,00$ & $13 / 09$ \\
\cline { 2 - 4 } (PSDB) - Não Eleito & Haroldo Azevedo Construções Ltda & $44.000,00$ & $19 / 07,25 / 09$ e 05/10 \\
\cline { 2 - 4 } & Haroldo Cavalcanti Azevedo & $55.146,00$ & $16,22 / 08,13,15,21,25 / 09,10 / 10$ \\
\cline { 2 - 4 } & Klabin S/A & $30.000,00$ & $29 / 09$ \\
\cline { 2 - 4 } & Fontes não identificadas & $279.037,39$ & $21 / 08,19,22 / 09$ \\
\hline \multirow{5}{*}{$\begin{array}{c}\text { Fernando Bezerra } \\
\text { (PTB) - Não Eleito }\end{array}$} & Recursos próprios & $406.840,00$ & - \\
\cline { 2 - 4 } & Banco Itaú S/A & $100.000,00$ & $27 / 09$ e 20/10 \\
\cline { 2 - 4 } & BRAsa Mercadorias Futuros BM\&F & $30.000,00$ & $09 / 08$ \\
\cline { 2 - 4 } & Construtora Barbosa Melo & $100.000,00$ & $25 / 07$ \\
\cline { 2 - 4 } & Diretório Nacional e Regional PTB & $605.000,00$ & $13 / 09$ \\
\cline { 2 - 4 } & Recursos próprios & $989.500,00$ & - \\
\cline { 2 - 4 } & Flávio Gurgel Rocha & $150.000,00$ & - \\
\cline { 2 - 4 } & FRATELLI Vita Bebidas S/A & $80.000,00$ & $21 / 09$ \\
\cline { 2 - 4 } & Gerdau Aços Longos S/A & $100.000,00$ & $27 / 09$ \\
\cline { 2 - 4 } & IBS Inst. Brasileiro de Siderurgia & $150.000,00$ & $08 / 09$ \\
\cline { 2 - 4 } & Quatro Incorporações Ltda & $130.000,00$ & $22 / 09$ \\
\hline & Votorantim Participações S/A & $50.000,00$ & $03 / 08$ \\
\hline
\end{tabular}

Fonte: TSE, 2006.

Em relação às campanhas eleitorais municipais, os gastos podem ser menores, mas, às vezes, são mais elevados em termos proporcionais. Por exemplo, se compararmos as despesas dos candidatos a prefeitos da região do Seridó potiguar, na campanha eleitoral de 2004, em relação ao número de habitantes dos municípios, os gastos médios por habitante superaram consideravelmente as despesas médias dos candidatos à presidência da República e ao Governo do Estado em 2006, despesas essas já bastante elevadas. Há municípios que o gasto médio em relação ao número de habitantes chegou a aproximadamente $\mathrm{R} \$ 30,00$ o que representa um valor bastante considerável, ou seja, pode-se afirmar que o "preço do voto" é significativamente alto na região. Se levarmos em consideração o gasto médio da campanha eleitoral, por município, em relação ao número de eleitores, o "preço do voto" torna-se muito mais elevado.

Excetuando-se o candidato a prefeito de Jucurutu pelo PMDB, cuja prestação de contas não apresenta lançamentos, a soma das despesas dos demais candidatos na região do Seridó, por exemplo, totaliza $\mathrm{R} \$ 1.752 .506,56$, portanto, um valor bastante elevado para uma região pobre composta por 23 municípios e com pouco mais de 250 mil habitantes.

Ao analisar as receitas e despesas de alguns candidatos dos municípios da referida região chamam a atenção do pesquisador as seguintes situações: o candidato a prefeito de Cruzeta pelo PMDB apresentou a maior despesa de campanha em 2004, muito embora o município apresente menos de dez mil habitantes; sequencialmente, os demais candidatos que formam o grupo dos três maiores gastadores na campanha eleitoral das eleições municipais de 2004 foram: José Marcionilo Barros Lins Neto (PSB) de Currais Novos, segundo maior contingente populacional e segundo maior gasto; e Edimar Medeiros Dantas (PFL) de Jardim do Seridó. Na sequência, Rivaldo Costa (PL) de Caicó, município que apresenta o maior número de habitantes na região, aparece em quarto lugar em gastos de campanha; Antônio Soares de Araújo (PDT) de Jardim de Piranhas; Pantaleão 
Estevam de Medeiros (PMDB) de Carnaúba dos Dantas; Antônio Petronilo Dantas Filho (PMDB) de Parelhas; Rogério Bezerra Mariz (PSB) de Serra Negra do Norte; José Rangel de Araújo (PT) de Caicó e Romildo Azevedo Santos (PTB) de Parelhas. Desses candidatos, dois não foram eleitos: José Rangel de Araújo (PT) de Caicó e Romildo Azevedo Santos (PTB) de Parelhas.

Em relação às fontes de recursos que cobriram os gastos dos candidatos a prefeito da campanha eleitoral de 2004 na região, confirma-se o poder das elites locais e regionais, haja vista as doações feitas pelos parentes dos candidatos, além de doações de comerciantes, funcionários públicos, proprietários de terras e políticos estaduais.

Chama especialmente a atenção do pesquisador, outras situações como: o então secretário de desenvolvimento econômico do estado, eleito deputado federal em 2006, João Maia, seridoense, de Jardim de Piranhas, doou valores bastante representativos a três candidatos da região - Juarez Bezerra de Medeiros (PL) de Acari, José Marcionilo Barros Lins Neto (PSB) de Currais Novos, e Ricardo Barbalho Azevedo (PSB) de Santana do Seridó. Diante disso, percebemos a relação entre agentes políticos locais e estaduais que refletem diretamente na configuração e/ou manutenção dos territórios conservadores de poder na região, no estado e no Brasil. Nesses municípios, o candidato a deputado federal referido acima obteve votações expressivas, revelando mais uma vez a importância do dinheiro para a obtenção de votos, por conseguinte o seu preço.

Em Caicó, município com o maior número de eleitores da região, um único contribuinte financiou $43 \%$ das despesas de campanha do candidato eleito. Tal candidato declarou ter custeado $26 \%$ da campanha, além de ter recebido R $\$ 10$ mil de uma distribuidora de medicamentos, e várias doações de pessoas físicas e pequenas empresas. Vale assinalar que existe inter-relação desse candidato com o segmento de saúde, tendo em vista que o mesmo foi diretor do Hospital do Seridó, instituição filantrópica cuja responsabilidade maior é do Deputado Vivaldo Costa, irmão do referido candidato, ex-governador do estado. Em Carnaúba dos Dantas, o candidato eleito declarou ter recebido mais de $97 \%$ da receita de apenas duas empresas, a Arosuco - Aromas e Sucos S/A, de Manaus-AM, e a Votorantim participações S/A. Cabe um questionamento diante desse fato: o que justificaria uma empresa da Amazônia e outra do centro-sul do Brasil financiar a campanha eleitoral de candidatos numa região do sertão nordestino como a região do Seridó? Isso possivelmente sinaliza para ligações políticas e/ou financeiras com tais agentes, isto é, candidatos locais (ou estaduais/nacionais) com tais empresários.

O candidato a prefeito, eleito pelo PMDB de Cruzeta, que teve a campanha mais cara em valor absoluto, face aos demais candidatos, declarou, em sua receita, aproximadamente $70 \%$ dos recursos como sendo oriundos do supermercado de sua propriedade, localizado na Região Metropolitana de Natal, e aproximadamente $30 \%$ da receita doada pelo supermercado do irmão, localizado no próprio município, instituição essa que em determinados momentos se constituiu prestadora de serviços para a prefeitura do município. O candidato do PT naquele município recebeu apenas uma doação com valor mais representativo, tendo que custear a maior parte da campanha com recursos próprios. No Seridó, vários candidatos declararam autofinanciamento de campanha, alguns desses, concorreram à reeleição e foram reeleitos.

Diante dessas afirmações, ressaltamos que o dinheiro é de fundamental importância para a manutenção dos "currais eleitorais", principalmente, nos municípios onde a população é predominantemente pobre e a taxa de analfabetismo é mais acentuada. Em geral, os candidatos que mais arrecadam, portanto, que mais gastam nas campanhas eleitorais, são eleitos, ou, no mínimo, muito bem votados. Por isso é que o dinheiro se constitui numa condição sine qua non à manutenção e "conservação" dos grupos e agentes políticos, haja vista os pactos e os acordos que são firmados, durante e após as eleições. Os valores doados pelas empresas aos candidatos dão uma boa prova da relação simbiótica existente entre os políticos, que se dizem representantes públicos, e o setor privado, que se beneficia do Estado através da "captura" daquilo que se constitui como recurso "público", que consequentemente deixa de beneficiar a totalidade da sociedade. 
Estima-se que somados os gastos das campanhas eleitorais de quase duas décadas, portanto, de 1994 a 2012, com base nas eleições de 1996, 1998, 2000, 2002, 2004, 2005 (referendo) e 2006, 2010 e 2012, tais gastos totalizam aproximadamente R\$ 10 bilhões, o que seria suficiente para resolver muitos problemas sociais no Brasil, por exemplo, problemas de saúde, os quais têm se agravado nos últimos anos em diversas regiões.

Vale frisar que no referendo realizado em 2005, os valores arrecadados na campanha eleitoral da Frente Parlamentar "Pelo direito da legítima defesa", ou seja, pelo grupo que votou e fez campanha pelo NÃO desarmamento do país, arrecadou R\$ 5.726.491,95. Desse total, R\$ 5.582.259,37, isto é, $97,5 \%$ originaram-se da doação de apenas dois grupos econômicos que detém a maior parte do mercado de armas e munições do país - Forjas Taurus S/A e Companhia Brasileira de Cartuchos. Enquanto isso, a Frente Parlamentar "Por um Brasil sem armas", que votou SIM, e fez campanha pelo desarmamento, arrecadou R $\$ 1.970 .311,00$. Portanto, o financiamento da campanha desse referendo deixa claro o quanto o interesse econômico, não raro, entrecruza-se com os interesses políticos, numa relação de reciprocidade e beneficiamento mútuo.

No tocante às eleições de 2010, as receitas e despesas também se mostram bastante elevadas entre os candidatos, seguindo a tendência das campanhas eleitorais anteriores quanto a volume de dinheiro e fontes de financiamento (Tabela 5).

Tabela 5 - Rio Grande do Norte: Receitas e despesas da campanha eleitoral, votação, situação e percentual de votos por candidato, 2010

\begin{tabular}{|c|c|c|c|c|c|c|}
\hline Candidato & Candidatura & Receita & Despesa & Situação & Votação & $\%$ \\
\hline Rosalba Ciarlini Rosado - DEM & Governador & $\mathrm{R} \$ 5.646 .040,00$ & $\mathrm{R} \$ 5.646 .006,37$ & Eleita & 813.813 & 52,46 \\
\hline Ibere Paiva Ferreira de Souza - PSB & Governador & $\mathrm{R} \$ 5.720 .687,16$ & $\mathrm{R} \$ 5.719 .425,29$ & Não eleito & 562.256 & 36,25 \\
\hline Carlos Eduardo Nunes Alves - PDT & Governador & $\mathrm{R} \$ 640.259,82$ & $\mathrm{R} \$ 640.229,98$ & Não eleito & 160.828 & 10,37 \\
\hline Sandro de Oliveira Pimentel - PSOL & Governador & $\mathrm{R} \$ 5.438,96$ & $\mathrm{R} \$ 5.438,96$ & Não eleito & 10.520 & 0,68 \\
\hline José Walter Xavier - PCB & Governador & $\mathrm{R} \$ 890,00$ & $\mathrm{R} \$ 840,00$ & Não eleito & 2.078 & 0,13 \\
\hline Bartolomeu da Silva Moreira - PRTB & Governador & $79.500,00$ & $\mathrm{R} \$ 79.500,00$ & Não eleito & 1.746 & 0,11 \\
\hline Veronica Simone Dutra Veras - PSTU & Governador & $\mathrm{R} \$ 6.445,00$ & $\mathrm{R} \$ 6.146,00$ & Não eleita & Cassada & \\
\hline Carlos Roberto Ronconi - PTC & Governador & $\mathrm{R} \$ 500,00$ & $\mathrm{R} \$ 500,00$ & Não eleito & Cassado & \\
\hline Garibaldi Alves Filho - PMDB & Senador & $\mathrm{R} \$ 3.662 .893,94$ & $\mathrm{R} \$ 3.662 .893,00$ & Eleito & & 35,03 \\
\hline José Agripino Maia - DEM & Senador & $\mathrm{R} \$ 4.825 .483,59$ & $\mathrm{R} \$ 4.975 .092,57$ & Eleito & 958.891 & 32,23 \\
\hline Wilma Maria de Faria - PSB & Senador & $\mathrm{R} \$ 3.596 .700,00$ & $\mathrm{R} \$ 3.596 .243,79$ & Não eleita & 651.358 & 21,89 \\
\hline Hugo Manso Junior - PT & Senador & $\mathrm{R} \$ 111.655,85$ & $\mathrm{R} \$ 111.628,48$ & Não eleito & 224.125 & 7,53 \\
\hline Joanilson de Paula Rêgo - PSDC & Senador & $\mathrm{R} \$ 47.776,76$ & $\mathrm{R} \$ 47.776,76$ & Não eleito & 66.408 & 2,23 \\
\hline Sávio Ximenes Hackradt - PC do B & Senador & $\mathrm{R} \$ 71.970,00$ & $\mathrm{R} \$ 71.953,15$ & Não eleito & 25.783 & 0,87 \\
\hline Antonio Ronaldo Gomes Garcia - PSOL & Senador & $\mathrm{R} \$ 4.020,00$ & $\mathrm{R} \$ 4.020,00$ & Não eleito & 6.639 & 0,22 \\
\hline Alexandre Guedes Fernandes - PSTU & Senador & $\mathrm{R} \$ 2.895,00$ & $\mathrm{R} \$ 2.637,00$ & Não eleito & Cassado & \\
\hline Dário Barbosa de Melo - PSTU & Senador & $\mathrm{R} \$ 3.810,00$ & $\mathrm{R} \$ 3.625,00$ & Não eleito & Cassado & \\
\hline Clóvis Ferreira da Costa - PTC & Senador & Não encontrado & Não encontrado & Não eleito & Cassado & \\
\hline Gualter Alencar do Couto - PRTB & Senador & Não encontrado & Não encontrado & & & \\
\hline Maria de Fátima Bezerra - PT & Dep. Federal & $\mathrm{R} \$ 472.742,58$ & $\mathrm{R} \$ 472.742,58$ & Eleita & 220.355 & 13,33 \\
\hline João da Silva Maia - PR & Dep. Federal & $\mathrm{R} \$ 1.134 .415,86$ & $\mathrm{R} \$ 1.134 .383,86$ & Eleito & 217.854 & 13,18 \\
\hline Henrique Eduardo Lyra Alves - PMDB & Dep. Federal & $\mathrm{R} \$ 3.363 .330,00$ & $\mathrm{R} \$ 3.363 .327,21$ & Eleito & 191.110 & 11,56 \\
\hline Fábio Salustino Mesquita de Faria - PMN & Dep. Federal & $\mathrm{R} \$ 1.415 .087,20$ & $\mathrm{R} \$ 1.415 .036,47$ & Eleito & 156.688 & 9,48 \\
\hline Felipe Catalão Maia - DEM & Dep. Federal & $\mathrm{R} \$ 1.759 .900,00$ & $\mathrm{R} \$ 1.757 .014,39$ & Eleito & 137.494 & 8,32 \\
\hline Carlos Alberto de Sousa Rosado - DEM & Dep. Federal & $\mathrm{R} \$ 352.485,00$ & $\mathrm{R} \$ 375.697,24$ & Eleito & 109.627 & 6,63 \\
\hline Sandra Maria da Escossia Rosado - PSB & Dep. Federal & $\mathrm{R} \$ 599.601,00$ & $\mathrm{R} \$ 599.588,98$ & Eleita & 92.746 & 5,61 \\
\hline Paulo Wagner Leite Dantas - PV & Dep. Federal & $\mathrm{R} \$ 429.458,93$ & $\mathrm{R} \$ 429.397,38$ & Eleito & 55.086 & 3,33 \\
\hline Antônio Jácome de Lima Júnior - PMN & Dep. Estadual & $\mathrm{R} \$ 480.892,00$ & $\mathrm{R} \$ 480.609,71$ & Eleito & 54.743 & 3,18 \\
\hline
\end{tabular}




\begin{tabular}{|c|c|c|c|c|c|c|}
\hline Ezequiel Galvão Ferreira de Souza - PTB & Dep. Estadual & $\mathrm{R} \$ 329.500,00$ & $\mathrm{R} \$ 329.414,29$ & Eleito & 51.842 & 3,01 \\
\hline Walter Pereira Alves - PMDB & Dep. Estadual & $\mathrm{R} \$ 780.230,00$ & $\mathrm{R} \$ 780.222,24$ & Eleito & 50.587 & 2,94 \\
\hline Ricardo José Meirelles da Motta - PMN & Dep. Estadual & $\mathrm{R} \$ 528.843,68$ & $\mathrm{R} \$ 528.843,68$ & Eleito & 49.881 & 2,9 \\
\hline Gustavo Henrique Lima de Carvalho - PSB & Dep. Estadual & $\mathrm{R} \$ 386.387,91$ & $\mathrm{R} \$ 386.348,44$ & Eleito & 49.850 & 2,89 \\
\hline Luiz Antônio L.de Farias (Tomba) - PSB & Dep. Estadual & $\mathrm{R} \$ 329.732,78$ & $\mathrm{R} \$ 329.528,84$ & Eleito & 49.832 & 2,89 \\
\hline Francisco Gilson de Moura - PV & Dep. Estadual & $\mathrm{R} \$ 554.628,00$ & $\mathrm{R} \$ 554.245,22$ & Eleito & 49.494 & 2,87 \\
\hline Nelter Lula de Queiroz Santos - PMDB & Dep. Estadual & $\mathrm{R} \$ 715.147,27$ & $\mathrm{R} \$ 715.147,27$ & Eleito & 49.364 & 2,87 \\
\hline Gesanne Borges Marinho Dantas - PMN & Dep. Estadual & $\mathrm{R} \$ 481.875,98$ & $\mathrm{R} \$ 481.837,35$ & Eleita & 48.440 & 2,81 \\
\hline Getulio Nunes do Rego - DEM & Dep. Estadual & $\mathrm{R} \$ 236.315,00$ & $\mathrm{R} \$ 236.315,00$ & Eleito & 43.697 & 2,54 \\
\hline Dibson Antonio Bezerra Nasser - PSDB & Dep. Estadual & $\mathrm{R} \$ 732.145,18$ & $\mathrm{R} \$ 732.145,18$ & Eleito & 41.883 & 2,43 \\
\hline Larissa Daniela da Escossia Rosado - PSB & Dep. Estadual & $\mathrm{R} \$ 368.219,70$ & $\mathrm{R} \$ 368.214,26$ & Eleita & 41.609 & 2,42 \\
\hline Leonardo da Vinci Lima Nogueira - DEM & Dep. Estadual & $\mathrm{R} \$ 406.162,00$ & $\mathrm{R} \$ 406.140,45$ & Eleito & 41.133 & 2,39 \\
\hline Márcia Faria Maia Mendes - PSB & Dep. Estadual & $\mathrm{R} \$ 523.870,00$ & $\mathrm{R} \$ 523.778,42$ & Eleita & 38.554 & 2,24 \\
\hline Vivaldo Silvino da Costa - PR & Dep. Estadual & $\mathrm{R} \$ 185.432,79$ & $\mathrm{R} \$ 185.432,79$ & Eleito & 38.463 & 2,23 \\
\hline Gustavo Regio Torquato Fernandes - PMDB & Dep. Estadual & $\mathrm{R} \$ 259.402,00$ & $\mathrm{R} \$ 259.359,61$ & Eleito & 37.907 & 2,2 \\
\hline Raimundo Nonato Pessoa Fernandes - PMN & Dep. Estadual & $\mathrm{R} \$ 288.000,00$ & $\mathrm{R} \$ 288.000,00$ & Eleito & 37.158 & 2,16 \\
\hline George Montenegro Soares - PR & Dep. Estadual & $\mathrm{R} \$ 441.923,32$ & $\mathrm{R} \$ 441.787,87$ & Eleito & 36.952 & 2,15 \\
\hline Fabio Berckmans Veras Dantas - PHS & Dep. Estadual & $\mathrm{R} \$ 271.058,03$ & $\mathrm{R} \$ 271.018,48$ & Eleito & 35.374 & 2,05 \\
\hline Hermano da Costa Moraes - PMDB & Dep. Estadual & $\mathrm{R} \$ 568.342,00$ & $\mathrm{R} \$ 568.087,76$ & Eleito & 35.294 & 2,05 \\
\hline Francisco Potiguar Cavalcanti Junior - PMDB & Dep. Estadual & $\mathrm{R} \$ 476.813,50$ & $\mathrm{R} \$ 476.415,32$ & Eleito & 31.881 & 1,85 \\
\hline Agnelo Alves - PDT & Dep. Estadual & $\mathrm{R} \$ 260.383,96$ & $\mathrm{R} \$ 260.236,00$ & Eleito & 30.995 & 1,80 \\
\hline José Dias de Souza Martins - PMDB & Dep. Estadual & $\mathrm{R} \$ 274.137,39$ & $\mathrm{R} \$ 274.137,39$ & Eleito & 30.876 & 1,79 \\
\hline Fernando Wanderley V. Silva (mineiro) - PT & Dep. Estadual & $\mathrm{R} \$ 170.100,00$ & $\mathrm{R} \$ 169.076,81$ & Eleito & 24.718 & 1,44 \\
\hline
\end{tabular}

Fonte: TSE, 2010.

Juntos os candidatos a governador do estado do Rio Grande do Norte apresentaram um montante de despesas superior a 12 milhões de reais, com forte disparidade entre alguns candidatos. Novamente os candidatos que apresentaram o maior volume de gastos foram os mais bem sucedidos nas eleições, a exemplo dos candidatos ao governo que disputaram as eleições no segundo turno, bem como os candidatos ao senado.

Quanto as eleições para deputado federal e deputado estadual seguiu-se a mesma tendência, isto é, os candidatos que apresentaram maiores despesas e receitas foram os que obtiveram melhores resultados nas eleições, salvo uma exceção, isto é, fogiu a regra apenas a candidata eleita pelo PT. Tem-se ainda uma situação bastante reveladora, isto é, um único candidato a deputado federal gastou sozinho mais de 3 milhões de reais. É justamente esse candidato o único que tem conseguido se manter na câmara federal há onze mandatos, um dos membros do legislativo federal com o maior tempo no cargo. Segue-se, portanto uma mesma lógica "mercantil" no processo eleitoral no Brasil, isto é, o número de votos de um candidato e sua reprodução política está diretamente relacionado ao montante de recursos gastos.

Cabem aqui vários questionamentos, entre eles, qual o nível de preocupação e comprometimento social de um candidato que ao se eleger já não se sente em débito perante a sociedade, tendo em vista o preço pago pelo seu quantitativo de votos? Ou seja, essa situação evidencia a necessidade de revisão da normativa que autoriza e estabelece critérios quanto ao financiamento das campanhas eleitorais no Brasil. Além, é claro, da necessidade de maior rigor no processo de fiscalização da prestação de contas, tendo em vista que esse volume de recursos declarados nem sempre corresponde ao volume real dos gastos em sua totalidade.

No que concerne às doações concedidas a candidatos ao governo estadual na campanha eleitoral de 2010, as fontes de financiamentos não destoam da tessitura das campanhas eleitorais anteriores, isto é, as fontes são praticamente as mesmas, indústrias, bancos, agentes financeiros, empreiteiras do governo, construtoras, empresas e empresários de vários setores da economia, agentes políticos, etc. (Tabela 6). 
Tabela 6 - Rio Grande do Norte: Principais doações da campanha eleitoral - candidatos ao governo, 2010

\begin{tabular}{|c|c|c|c|}
\hline Candidato / Partido & Fonte de Recursos & Valor (R\$) & Data \\
\hline \multirow{9}{*}{ Rosalba Ciarlini Rosado / DEM } & Itagres Revestimentos Cerâmicos S/ A & $50.000,00$ & $12 / 08 / 2010$ \\
\hline & Itaú Unibanco S/A & $100.000,00$ & $05 / 08 / 2010$ \\
\hline & $\begin{array}{l}\text { M. Dias Branco S.A. Industria e Comercio de } \\
\text { Alimentos }\end{array}$ & $150.000,00$ & $30 / 07 / 2010$ \\
\hline & Pedreira Potiguar Ltda. ME & $170.100,00$ & $16 / 07 / 2010$ \\
\hline & Salinor Salinas do Nordeste S/A & $110.000,00$ & $24 / 08 / 2010$ \\
\hline & $\begin{array}{l}\text { Toniolo Busnello S/A Tuneis Terraplenagens e } \\
\text { Pavimentação }\end{array}$ & $50.000,00$ & $27 / 09 / 2010$ \\
\hline & Três Corações Alimentos S.A & $200.000,00$ & $22 / 07 / 10$ e $02 / 09 / 2010$ \\
\hline & Vicunha Têxtil S/A & $250.000,00$ & $20 / 09 / 2010$ \\
\hline & Votorantim Industrial S A & $300.000,00$ & $01 / 10 / 2010$ \\
\hline \multirow{18}{*}{$\begin{array}{l}\text { Iberê Paiva Ferreira de Souza / } \\
\text { PSB }\end{array}$} & A. Azevedo da Silva & $100.000,00$ & $27 / 10 / 2010$ \\
\hline & Alesat Combustíveis S/A & $200.000,00$ & $03 / 08 / 2010$ \\
\hline & BMG Leasing S/A Arrendamento Mercantil & $450.000,00$ & $03 / 09 / 2010$ \\
\hline & Cia Hering & $50.000,00$ & $22 / 09 / 2010$ \\
\hline & Comercial de Laticínios de Natal Ltda. & $55.000,00$ & $31 / 08,22 / 10$ e $25 / 10 / 2010$ \\
\hline & Comercio ME Ltda. & $100.000,00$ & $19 / 08 / 10$ e $23 / 08 / 2010$ \\
\hline & Construtora Ramalho Moreira & $100.000,00$ & $29 / 10 / 2010$ \\
\hline & Contremac Construções Ltda. & $85.000,00$ & $31 / 08 / 2010$ \\
\hline & Ecocil Empresa de Construções Civis Ltda. & $200.000,00$ & $30 / 09 / 2010$ \\
\hline & Galvão Engenharia S/A & $200.000,00$ & $17 / 09 / 2010$ \\
\hline & Garra Vigilância Ltda. & $90.000,00$ & $27 / 10 / 2010$ \\
\hline & Laticínios São Pedro Ltda. & $70.000,00$ & $25 / 10 / 2010$ \\
\hline & M \& K Com e Construções Ltda. & $50.000,00$ & $05 / 10 / 2010$ \\
\hline & $\begin{array}{l}\text { M Dias Branco S/A Industria e Comercio de } \\
\text { Alimentos }\end{array}$ & $200.000,00$ & $26 / 07 / 2010$ \\
\hline & Pedreira Potiguar Ltda. ME & $50.000,00$ & $08 / 09 / 2010$ \\
\hline & Salinor Salinas do Nordeste S/A & $90.000,00$ & $24 / 08 / 2010$ \\
\hline & Suprinor Suprimentos do Nordeste Ltda.-Me & $80.000,00$ & $27 / 10 / 2010$ \\
\hline & Wilma Maria de Faria & $200.000,00$ & $17 / 09 / 2010$ \\
\hline Carlos Eduardo N. Alves / PDT & Salinor Salinas do Nordeste S/A & $50.000,00$ & $24 / 08 / 2010$ \\
\hline
\end{tabular}

Fonte: TSE, 2010.

Já o quadro geral do financiamento da campanha eleitoral dos candidatos ao senado da república em 2010, no Rio Grande do Norte, apresenta novos agentes em cena, a exemplo do grupo Sky Brasil, um dos maiores do mundo no setor de mídia e telecomunicações (Tabela 7).

Diante do exposto é visível a relação entre o setor privado, o qual financia as campanhas eleitorais no Brasil doando volumes consideráveis de recursos aos candidatos, e o próprio Estado, capturado por esses agentes e seus "beneficiários", embora as vezes estes se confundam, isto é, o candidato é o próprio empresário, seja ele industrial, banqueiro, comerciante, latifundiário ou construtor. 
Tabela 7 - Rio Grande do Norte: Principais doações da campanha eleitoral - candidatos (a) ao senado da República, 2010

\begin{tabular}{|c|c|c|c|}
\hline Candidato / Partido & Fonte de Recursos & Valor (R\$) & Data \\
\hline \multirow{7}{*}{ Garibaldi Alves Filho / PMDB } & ASA Industria e Comercio Ltda. & $100.000,00$ & $03 / 09 / 2010$ \\
\hline & Construtora Sucesso S/A & $147.700,00$ & $22 / 10$ e $29 / 10 / 2010$ \\
\hline & Itaú Unibanco S/A & $200.000,00$ & $26 / 08 / 2010$ \\
\hline & Salinor - Salinas do Nordeste S/A & $70.000,00$ & $24 / 08 / 2010$ \\
\hline & Sky Brasil Serviços & $50.000,00$ & $10 / 09 / 2010$ \\
\hline & TAL Empreendimentos Imobiliários Ltda. & $50.000,00$ & $29 / 09 / 2010$ \\
\hline & Três Corações Alimentos S/A & $60.000,00$ & $20 / 09 / 2010$ \\
\hline \multirow{13}{*}{ José Agripino Maia / DEM } & Arosuco Aromas e Sucos S/A & $70.000,00$ & $24 / 08 / 2010$ \\
\hline & Banco Fator S/A & $100.000,00$ & $10 / 08 / 2010$ \\
\hline & Bunge Fertilizantes S.A. & $100.000,00$ & $10 / 09 / 2010$ \\
\hline & Companhia Metalúrgica Prada & $300.000,00$ & $31 / 08 / 2010$ \\
\hline & EIT Empresa Industrial Técnica S/A & $550.000,00$ & $22 / 09$ e $26 / 10 / 2010$ \\
\hline & Gerdau Comercial de Aços S/A & $150.000,00$ & $23 / 08 / 2010$ \\
\hline & Itaú Unibanco S.A. & $200.000,00$ & $10 / 08 / 2010$ \\
\hline & Lojas Riachuelo S.A. & $50.000,00$ & $28 / 09 / 2010$ \\
\hline & Pedreira Potiguar Ltda. & $72.900,00$ & $16 / 07 / 2010$ \\
\hline & Rosalba Ciarlini Rosado & $69.549,99$ & $\begin{array}{c}16 / 07,24 / 07,27 / 07 \mathrm{e} \\
16 / 09 / 2010\end{array}$ \\
\hline & Sky Brasil Serviços Ltda. & $60.000,00$ & $10 / 09 / 2010$ \\
\hline & Usiminas Mecânica S/A & $169.000,00$ & $10 / 09 / 2010$ \\
\hline & Votorantim Industrial S.A. & $120.000,00$ & $10 / 09 / 2010$ \\
\hline \multirow{9}{*}{ Wilma Maria de Faria / PSB } & Alesat Combustíveis S/A & $340.000,00$ & $\begin{array}{c}11 / 08,25 / 08,03 / 09 \text { e } \\
24 / 09 / 2010\end{array}$ \\
\hline & Construções e Comercio Camargo Correia S/A & $500.000,00$ & $15 / 09 / 2010$ \\
\hline & Construtora Marquise S/A & $70.000,00$ & $25 / 08 / 2010$ \\
\hline & Delphi Engenharia Ltda. & $150.000,00$ & $27 / 07,20 / 09$ e $21 / 09 / 2010$ \\
\hline & Guararapes Confecções S/A & $50.000,00$ & $29 / 09 / 2010$ \\
\hline & Industria e Comercio Metalúrgica Atlas S/A & $100.000,00$ & $06 / 10 / 2010$ \\
\hline & $\begin{array}{l}\text { M Dias Branco S/A Industria e Comercio de } \\
\text { Alimentos }\end{array}$ & $100.000,00$ & $15 / 09 / 2010$ \\
\hline & Salinor-Salinas Nordeste S/A & $70.000,00$ & $24 / 08 / 2010$ \\
\hline & Três Corações Alimentos S/A & $161.000,00$ & $30 / 08$ e $08 / 09 / 2010$ \\
\hline
\end{tabular}

Fonte: TSE, 2010.

\section{A TROCA DE FAVOR: o uso ilícito do cargo e do recurso público}

Diante do que foi analisado até aqui, é possível observar que os candidatos eleitos a partir do financiamento de campanhas com doações de empresas privadas, quase sempre, adotam uma postura de retribuição do favor prestado por essas, seja "facilitando a vida" dessas empresas mediante a criação de legislações que as favoreçam, seja através de tráfego de influências ou de informações privilegiadas às mesmas. Assim, nota-se que geralmente os gastos, quase sempre financiados por empresas e pessoas físicas, podem ter relação, direta ou indireta, com o peculato e com o desvio de recursos públicos através de corrupção política, ativa ou passiva.

As Comissões Parlamentares de Inquéritos podem se constituir numa alternativa para constatar e revelar oficialmente o problema, e isso tem ocorrido no Brasil, a exemplo do que se verificou e se está verificando no episódio que ficou conhecido como "mensalão", porém, quando concluídos os trabalhos de investigação, e comprovadas as fraudes, nem sempre a punição dos culpados acontece

No Rio Grande do Norte, a Comissão Parlamentar de Inquérito, que se tornou conhecida 
como "CPI do leite", confirmou em seu relatório final, publicado no Diário Oficial do Estado em 30/01/2004, que as irregularidades apontadas no relatório da Comissão Especial de Auditoria do Programa do Leite, anterior à CPI, eram verossímeis. A partir do referido relatório, requereu-se a instauração da CPI através da Assembléia Legislativa do estado. Tal requerimento, de iniciativa do deputado estadual Wober Júnior (PPS), membro da base aliada da então governadora, e subscrito por outros doze deputados oposicionistas ao ex-governador Garibaldi Alves (PMDB), "se baseia numa série de ilegalidades cometidas na execução do Programa do Leite no período de 1995 a 31 de dezembro de 2002", descritas no referido relatório e elaborado pela comissão especial de auditoria da Secretaria de Estado de Ação Social (DOE-RN, 2004, p. 53). Nesses termos, o relatório oficial elaborado pela Comissão Parlamentar de Inquérito do Programa do Leite aponta:

a respaldar a proposição, elencaram os proponentes, em 07 (sete) itens, as ilegalidades cometidas na execução do Programa do Leite, no período compreendido entre dezembro de 1999 até dezembro de 2002 [...] 1) após análise dos processos de pagamento de prestações de contas, apresentados pela CERSEL, identificou-se diferença de valores pagos a maior, em relação à quantidade de litros/dia de leite autorizado pelos Termos 004/99 e seus aditivos. Somente no caso da CERSEL existe uma diferença a maior (autorizado x faturado) de R \$ 6.825.839,12 (seis milhões, oitocentos e vinte e cinco mil, oitocentos e trinta e nove reais e doze centavos). 2) após o cruzamento de informações extraídas dos processos de prestação de contas e do mapa de quantidades de áreas de leite distribuídas em cada posto, a diferença apontada é de $\mathrm{R} \$ 9.389 .779,12$ (nove milhões, trezentos e oitenta e nove mil, setecentos e setenta e nove reais e doze centavos); 3) $68,5 \%$ (sessenta e oito vírgula cinco por cento) dos beneficiários declararam que o leite fornecido pelo "Programa do Leite" coagula; 4) 66,67\% (sessenta e seis vírgula sessenta e sete por cento) do leite bovino usado pelo Programa foi encontrada a presença de coliformes fecais; 5) $39,9 \%$ (trinta e nove vírgula nove por cento) dos beneficiários afirmam que existem falhas na entrega do leite; 6) constatou-se que a quantidade de beneficiários, por município, pré-definida em $40 \%$ (quarenta por cento) do total de pessoas indigentes, foi desvirtuada principalmente a partir do período eleitoral de 1998; 7) 72,7\% (setenta e dois vírgula sete por cento) dos responsáveis pelos postos desconhecem a existência do quadro de associados, indicando um forte indício de que a distribuição do leite não era feita exclusivamente pelas entidades previamente credenciadas e sim por pessoas indicadas por lideranças locais. (DOE-RN, 2004, p. 53).

Diante do exposto, comprovam-se as premissas desse trabalho sobre a captura do Estado em benefício de determinados grupos e agentes políticos, impedindo maiores avanços e melhorias sociais. No caso do Programa do Leite, comprometeu-se também a saúde pública, especialmente da população carente assistida, haja vista a qualidade do produto distribuído. Além disso, por se caracterizar como um Programa de base assistencialista, o mesmo serve duplamente à formação e manutenção dos "currais eleitorais", por um lado, quando incute no universo de famílias assistidas a sensação de favor prestado, e que, por isso, deve ser retribuído com o voto; por outro, quando gera receitas para os grupos e agentes que detêm o poder político e econômico, os quais, a cada processo eleitoral, usam de todos os meios e recursos para conseguirem se eleger. Percebemos que o valor supostamente desviado do Programa do Leite, no período citado, no referido relatório, é quase suficiente para cobrir as despesas da campanha eleitoral dos dois principais candidatos ao Governo do Estado em 2006.

Quanto aos resultados das investigações feitas pela CPI do Programa do Leite, notamos que depois de arroladas as provas - testemunhal, documental e técnica -, e concluído o processo investigatório, com base na metodologia adotada, foi elaborado um relatório final, o qual recomenda ao poder executivo estadual algumas medidas, das quais poucas foram efetivamente cumpridas, por exemplo, as proposições dos itens 15 e 18 que tratam de: "priorizar as aquisições de leite in natura a micros e pequenos produtores pecuaristas, que apresentarem produção média de até 100 litros/ dia e que estejam sediados na mesma região", e a aquela que determina que 
deve ser "descredenciado" como fornecedor do Programa do Leite, o Laticínio São Pedro Ltda (LEITE MARINA), tendo em vista a grande quantidade de leite em pó e soro de leite em pó adquiridos por tal empresa em vários estados da federação, conforme notas fiscais acostadas aos autos. Esta afirmação é corroborada em documento denominado Industrialização do Leite no Rio Grande do Norte, elaborado pelo SEBRAE/RN, e que se encontra nos autos. Isto significa que aludidos produtos podem ter sido usados para fraudar o leite do Programa. Além do mais, o relatório apresentado à CPI pela Comissão de Distribuição do Leite de Pedro Avelino/RN e que também se encontra nos autos, aponta que no ano de 2002, deixou de ser entregue pelo Laticínio São Pedro no município de Pedro Avelino, embora tenha recebido o respectivo pagamento, a quantia de 49.920 (quarenta e nove mil, novecentos e vinte) litros. (DOE-RN, 2004, p.54).

Sabe-se que algumas recomendações foram parcial ou totalmente atendidas, porém, sobre várias medidas, não obtivemos informações claras e precisas que comprovem suas resoluções. É importante frisar que o último item do relatório-síntese elaborado pela CPI do Programa do Leite, determina algumas providências a serem tomadas por parte de algumas instituições específicas do poder público, conforme o texto a seguir:

esta CPI, diante do término dos seus trabalhos de investigação e nos termos do art. 121 do regimento interno da Assembléia Legislativa, determina que cópias deste relatório sejam encaminhadas aos seguintes órgãos: 01. Ao poder executivo para a adoção das recomendações suso [sic] referidas; 02. A Procuradoria Geral do Estado para que promova as ações de ressarcimento necessárias; 03. Ao Ministério Público do Estado do Rio Grande do Norte para que adote as medidas judiciais que entender, com a sugestão respeitosa de que observe, julgando adequado, dente [sic] outros, os seguintes tópicos: a) a transformação ilegítima de contrato em convênio; b) as alterações determinadas no convênio, nas datas de 30 de janeiro de 2002 e 18 de novembro de 2002, com o desvirtuamento do Programa do Leite; c) a concentração do vínculo jurídico-administrativo do Programa do Leite com um único fornecedor: a CERSEL; d) a retenção, pela CERSEL, de $4,78 \%$ de todo o faturamento das usinas fornecedoras de leite; e) a ocorrência, apurada, de pagamento a maior, que alcançaram o valor de $\mathrm{R} \$ 9.389 .777,12$ (nove milhões, trezentos e oitenta e nove mil, setecentos e setenta e sete reais e doze centavos); f) a grande quantidade de leite em pó, soro de leite em pó, soro de leite e leite cru resfriado importados de outros estados da federação pela CLAN; g) a injustificável importação de leite em pó e soro de leite em pó pelo Laticínio São Pedro Ltda (LEITE MARINA), que sabidamente não produz bebidas lácteas,caracterizando nessa importação a intenção de fraude do Programa; h) a má qualidade do leite distribuído, com fraude por aguagem e desnate; com a inserção de bicarbonato de sódio; com características físico-químicas anômalas da densidade, gordura e acidez fora dos padrões; com a presença de conservantes, urina e coliformes fecais; com a constatação de que $66,67 \%$ do leite bovino apresentavam coliformes fecais; com apuração de que $95,24 \%$ do leite fornecido está fora dos padrões quanto ao teor de gordura; com a verificação de que $28,57 \%$ contém urina; com a aferição de que $19,05 \%$ contém bicarbonato; com o exame circunstanciado dos laudos nos. 09, 13, 26 e 37 de 2003, todos da lavra do Centro Federal de Educação Tecnológica do Rio Grande do Norte; com relação ao leite caprino verificar que $66,67 \%$ apresentam coliformes fecais e $100 \%$ exibem que o teor de gordura e a densidade estão fora dos padrões. 04. Ao Tribunal de Contas do Estado do Rio Grande do Norte para as providências de sua competência; 05. As Comissões Permanentes desta Assembléia - Finanças e Fiscalização e, Ciência e Tecnologia, Desenvolvimento Econômico e Social - para estudar as medidas pertinentes. (DOE-RN, 2004, p.54).

Das providências que foram sugeridas, sabe-se que poucas surtiram efeitos positivos em benefício da sociedade potiguar em geral. Por exemplo, o valor desviado não foi ressarcido aos cofres públicos, como também não houve punição de nenhum agente político, econômico ou responsável, direta ou indiretamente pelo Programa naquele período (dezembro de 1999 a dezembro de 2002). Ademais, não foram apurados os possíveis danos à saúde da população beneficiária do programa do leite, no que concerne ao consumo do leite adulterado. 


\section{CONSIDERAÇÕES FINAIS}

Das despesas de campanha declaradas pelos candidatos nas eleições analisadas, aparece uma diversidade de fins como: viagens, propaganda e publicidade, comícios, produções audiovisuais, serviços de terceiros, despesa com pessoal, locação de bens móveis e imóveis, cachês de artistas e animadores, camisetas, bonés e outros brindes (antes permitidos o uso), doações a outros candidatos ou comitês, combustíveis e lubrificantes, pesquisas de intenção de votos ou testes eleitorais, montagem de palanques e equipamentos, bens e materiais permanentes, correios, água, luz, telefone, lanches e refeições, dentre outras despesas.

Em meio a essas despesas, admitidas e reconhecidas pelos órgãos fiscalizadores, existem formas, nem sempre visíveis, que permitem burlar as prestações de contas, de modo que os recursos declarados podem ser utilizados para outros fins como: compra de votos, compra de bens e/ou serviços para serem doados aos eleitores, pagamento pelo apoio político de determinadas personalidades influentes nas bases locais e regionais, entre outras finalidades. Valores não declarados que supostamente constituem o "caixa dois", também podem servir para tais fins, o que evidencia um sistema marcado por corrupção e falta de ética na política partidária. Sistema esse que oprime e humilha a população e não contribui para a constituição da cidadania.

Ao relacionar as despesas das campanhas eleitorais brasileiras com as despesas de campanhas realizadas em países desenvolvidos, nota-se que o Brasil ultrapassa nações como Alemanha e Grã-Bretanha. Nota-se, também, que os financiadores geralmente são privados, principalmente construtoras e bancos, prestadoras de serviços aos governos, municipal, estadual ou federal. Ademais, os valores declarados são muitas vezes bastante superiores ao montante efetivamente transacionado. Observam-se ainda fortes disparidades entre partidos, e/ou entre candidatos, às vezes, de um mesmo partido. Em alguns casos, municípios com sérios problemas sociais, a exemplo de alguns localizados no interior do nordeste do país, apresentam um custo per capita superior a $\mathrm{R} \$ 30,00$, isto é, aproximadamente 10\% do valor do salário mínimo vigente em 2006.

Verifica-se ainda que a maior parte dos agentes políticos brasileiros está mais preocupada com seus próprios negócios e interesses, e com a manutenção de seus próprios privilégios e de suas carreiras políticas do que com as questões sociais e a gestão pública, até porque normalmente pagam caro para serem eleitos, mesmo que tais recursos não sejam próprios, mas do Estado. Significado dizer que se estes pagam pelo voto da população, os mesmos se sentem desobrigados de atuar em prol da sociedade em sua totalidade.

Nesse contexto, preservar e manter os problemas sociais (educacionais, habitacionais e no setor de saúde, principalmente) se constitui numa condição primordial para que as necessidades sempre existam e, portanto, as relações de troca - favor-voto - se estabeleçam e se reproduzam.

Os gastos exorbitantes das campanhas eleitorais brasileiras demonstram que o sistema político em vigor "não se sustenta", haja vista que tais custos são normalmente arcados e transferidos para o conjunto da sociedade. Ao final, a sociedade é quem arca com "ônus" das despesas dos candidatos. Geralmente, quem mais arrecada e, portanto, quem mais gasta, se elege. Os financiadores são, não raro, as empresas prestadoras de serviços ao setor público, ou seus respectivos donos, como também, o próprio setor público, através dos fundos partidários destinados para esse fim.

Além dos recursos provenientes de tais fontes, os candidatos ainda gastam volumes substanciais de capital "próprio" ou de suas empresas, os quais também são transferidos, de alguma forma, para a sociedade. Tais gastos, lícitos ou ilícitos, somam valores extremamente elevados, tendo em vista a realidade social brasileira. Somando os recursos que custearam as campanhas eleitorais do período 1996-2010, pode-se afirmar que o montante auferido seria suficiente para resolver vários problemas sociais do país.

Diante desse quadro, se faz urgente que algumas medidas sejam adotadas no sentido de gerar possibilidades de mudanças sociais mais amplas para a realidade observada. É de fundamental importância que se altere o conjunto de relações que configura o sistema político brasileiro, podendo- 
-se começar pela despersonificação de tudo que é público: obras, benefícios de programas sociais, fomento de projetos de desenvolvimento, enfim, toda e qualquer ação do setor público, portanto, do Estado. Dessa forma, será possível alterar, em certa medida, a cultura política caracterizada pelo clientelismo, assistencialismo e relações de trocas de favores; para isso, uma reforma política amplamente discutida, participativa e construída envolvendo as várias instâncias da sociedade, será fundamental.

A despersonificação das ações do Estado pode ser feita através, por exemplo, da adoção de um sistema eleitoral no qual o voto deixe de ser obrigatório, mas livre, supondo-se que votará livremente, e de forma consciente, sobretudo a população mais preocupada com a política nacional e com as questões sociais em sua totalidade. Vale ressaltar que o sistema eleitoral vigente no Brasil encontra-se em vigor desde 1945, período em que o país vivia uma das fases iniciais do processo de democratização.

Os gastos dos candidatos nas campanhas eleitorais, cuja maior parte dos valores é arcada pela sociedade, demonstram que o sistema eleitoral em vigor não se sustenta, ao menos para a sociedade, por isso, é essencial que se altere o modelo que vem sendo praticado. Talvez, com as mudanças sugeridas aqui consigamos reduzir tais custos, porém, enquanto isso não ocorre, é preciso normatizar as arrecadações lícitas e coibir as ilícitas, estabelecendo, assim, limites no que concerne às despesas das campanhas eleitorais.

Carece também mais transparência no processo de fiscalização dos gastos públicos. Poderiam ser criadas, por exemplo, comissões horizontais mistas especializadas no assunto, envolvendo a sociedade, e incumbidas de fiscalizar e controlar rigorosamente o emprego dos recursos públicos nas esferas de governo municipal, estadual e federal. É igualmente importante que todo o sistema de prestação de contas dos gastos públicos seja melhor normatizado e obrigatório, tornando-se, via de regra, acessível a toda a população, para que essa possa ter amplo conhecimento sobre o destino dos recursos públicos que são gastos.

Outra medida importante, diz respeito à adoção de um modelo de gestão pública horizontal e descentralizada, portanto, efetivamente democrática e transparente, envolvendo a participação popular no que se refere ao planejamento e à administração pública.

\section{REFERÊNCIA BIBLIOGRÁFICA}

ANDRADE, Ilza A. L. de. Políticas e poder: o discurso da participação. São Paulo: AD HOMINEM; Natal: Cooperativa Cultural da UFRN, 1996.

AZEVEDO, Francisco F. de. Entre a cultura e a política: uma geografia dos "currais" no sertão do Seridó Potiguar. 2007. 445 f. Tese. (Doutorado em Geografia) - Instituto de Geografia. Universidade Federal de Uberlândia, 2007.

BBC. Gasto eleitoral pode superar Grã-Bretanha e Alemanha. "Times New Roman","serif"'>[En línea]. BBC. Disponível em: <htpp://www.bbc.co.uk/portuguese/reporterbbc/story/2006/07/060705_gastocampnhabrasilmundo.shtml>. [Acesso em 15 dez 2006].

BETTO, Frei. A mosca azul: reflexões sobre o poder. Rio de Janeiro: Rocco, 2006.

BOBBIO, Norberto. Estado, governo, sociedade: para uma teoria geral da política. 12 ed. Tradução Marco Aurélio Nogueira. Rio de Janeiro: Paz e Terra, 2005.

BOFF, Leonardo. Depois de 500 anos: que Brasil queremos? 3. ed. Petrópolis: Vozes, 2003.

BOFF, Leonardo. Uma Plataforma para a utopia. In: CHAUI, Marilena et al. Leituras da crise: Diálogos sobre o PT, a democracia brasileira e o socialismo. São Paulo: Fundação Perseu Abramo, 2006. p. 201-255. BOURDIEU, Pierre. O poder simbólico. Tradução de Fernando Tomaz. 8. ed. Rio de Janeiro: Bertrand Brasil, 2005.

BUARQUE, Cristovam. A segunda abolição: um manifesto-proposta para a erradicação da pobreza no Brasil. 2. ed. São Paulo: Paz e Terra, 1999. 
BUARQUE, Cristovam. A desordem do progresso: o fim da era dos economistas e a construção do futuro. Rio de Janeiro: Paz e Terra, 1993.

CASTRO, Josué de. Geografia da fome. 6 ed. Rio de Janeiro: Civilização Brasileira, 2006.

CASTRO, Iná Elias de. Geografia e política. Território, escalas de ação e instituições. Rio de Janeiro: Bertrand Brasil, 2005.

CHARAUDEAU, Patrick. Discurso Político. Tradução de Fabiana Komesu e Dílson Fereira da Cruz. São Paulo: Contexto, 2006.

CHÂTELET, François ; DUHAMEL, Olivier; PISIER-KOUCHNER, Evelyne. História das ideais políticas. Tradução de Carlos Nelson Coutinho. Rio de Janeiro: Jorge Zahar, 2000.

CHAUI, Marilena. Cultura e democracia: o discurso competente e outras falas. São Paulo: Cortez, 2006. CONGRESSO EM FOCO. Bancos foram os principais doadores de Alckmin. [En línea]. Brasília: Congresso Nacional. Disponível em: <http://congressoemfoco.ig.com.br/Noticia.aspx?id=1274>. [Acesso em 15 Dez 2006a].

CONGRESSO EM FOCO. EMPREITEIRAS e bancos lideram financiadoras de Lula. [En línea]. Brasília: Congresso Nacional. Disponível em: <http://congressoemfoco.ig.com.br/Noticia.aspx?id=1274>. [Acesso em 15 Dez 2006b].

DEMO, Pedro. Pobreza da pobreza. Petrópolis: Vozes, 2003.

DEMO, Pedro. Pobreza política: a pobreza mais intensa da pobreza brasileira. Campinas: Armazém do Ipê (Autores Associados), 2006.

DOE-RN - Diário Oficial do Estado do Rio Grande do Norte. Relatório síntese da Comissão Parlamentar de Inquérito do Programa do Leite. Natal: Imprensa Oficial, 30/01/2004, p.52-54.

FAORO, Raimundo. Os donos do poder: formação do patronato político brasileiro. 10.ed. São Paulo: Globo; Publifolha, 2000. (v. 1 e 2. Grandes Nomes do Pensamento Brasileiro).

FIGUEIREDO FILHO, Dalson Britto. Gastos eleitorais: os determinantes das eleições? Estimando a influência dos gastos de campanha nas eleições de 2002. Revista Urutágua. Maringá. n. 8, dez/jan/fev/mar. 2006. Disponível em: <www.uem.br/urutagua/008/08>. [Acesso em 16 Dez 2006b].

FOUCAULT, Michel. Microfísica do poder. Tradução de Roberto Machado. Rio de Janeiro: Edições Graal, 2006.

IBGE - Instituto Brasileiro de Geografia e Estatística. Cidades. [En línea] Instituto Brasileiro de Geografia e Estatística. Disponível em: <http://www.ibge.gov.br/cidades/default.php>. [Acesso em 06 Set 2005].

IBGE. Censos Demográficos, 1991 e 2000. [En línea] Instituto Brasileiro de Geografia e Estatística. Disponível em: <http://www.sidra.ibge.gov.br>. [Acesso em 06 Set 2005].

CONSULTOR JURÍDICO. Saldo final tucanos batem recorde de gastos com campanha. [En línea]. São Paulo: Revista Consultor Jurídico. Disponível em: <http://conjur.estadao.com.br/static/text/4987,1>. [Acesso em 16 dezembro de 2006].

REVISTA ÉPOCA. Por que é tão caro? [En línea]. Rio de Janeiro: Editora Globo. Disponível em: $<$ htpp:// revistaepoca.globo.com/Revista/Epoca/0,,EDG75860-6009-446,00.html>. [Acesso em 16 Dez 2006].

SAMUELS, David. Financiamento de campanhas no Brasil e propostas de reforma no Brasil. In: SOARES, Gláucio Ary Dillon; RENNÓ, Lucio R. Reforma política: lições da história recente. Rio de Janeiro: FGV, 2006. p. 133-153.

SEN, Amartya. Desenvolvimento como liberdade. Tradução de Laura Texeira Motta - São Paulo: Companhia das Letras, 2000.

SETHAS - Secretaria de Estado do Trabalho, da Habitação e da Assistência Social. Relação de produtores do Programa do Leite por município. Natal, 2005a. (Digitado).

SETHAS. Manual de procedimento operacional. Programa do Leite. Natal, 2005b.

SETHAS. Relatório dos impactos sociais, econômicos e nutricionais do Programa do Leite. Natal, 2004. (Digitado)

SINDLEITE - Sindicato das Indústrias de Laticínios e Produtos Derivados do Rio Grande do Norte. Relação das indústrias de laticínios sindicalizadas. Natal, 2005. 
SINDLEITE. Controle de entrega das prestações de contas das indústrias de laticínios contratadas. Natal, 2005.

SILVA, Márcia da. Territórios conservadores de poder no centro-sul do Paraná. 2005. 263 f. Tese. (Doutorado em Geografia) - Faculdade de Ciências e Tecnologia, Universidade Estadual Paulista, Presidente Prudente, 2005.

SOARES, Gláucio A. D.; RENNÓ, Lucio R. Reforma política: lições da história recente. Rio de Janeiro: FGV, 2006.

TRE - Tribunal Regional Eleitoral do Rio Grande do Norte. Resultados das Eleições de 1996, 1998, 2000, 2002 e 2004. [En línea]. TRE/RN: Natal. Disponível em: $<$ http://www.tre.rn.gov.br >. [Acesso em 10 Set 2005]. TSE - Tribunal Superior Eleitoral. Sistema de prestação de contas das campanhas eleitorais de 2002, 2004 e 2006. [En línea]. TSE: Brasília. Disponível em: <http://www.tse.gov.br>. [Acesso em 17 Dez 2006]. TRIBUNA DO NORTE. Wilma recebe $34,3 \%$ das doações depois de eleita. [En línea]. Natal: Tribuna do Norte. Disponível em: <http://tribunadonorte.com.br/noticiaprint.php?id=28311>. [Acesso em 15 Dez 2006]. 